\title{
The relation of Babylonian astronomy to its culture and society
}

\author{
Hermann Hunger
}

\author{
Austrian Academy of Sciences, \\ Dr. Ignaz Seipel-Platz 2, 1010 Vienna, Austria \\ email: hermann.hunger@univie.ac.at
}

Babylonian astronomy is quite different from astronomy as it is customary today. We have to reconstruct it exclusively from texts and a few schematic drawings accompanying them. No instruments related to astronomy have been found. These texts are written on clay tablets in cuneiform script which was used in the Near East from ca. 3000 BCE to 100. It was completely forgotten and only deciphered in the middle of the 19th century. Since then, hundreds of thousands of clay tablets have been found in archaeological excavations, mostly in present-day Iraq. Among these are a few thousand tablets related to astronomy. Many have been published, but more still need to be worked on. And of course an unknown number of such texts is still buried under the sands of Iraq.

There were no telescopes then; only what can be seen with the naked eye was accessible, but on the other hand there was no light pollution. Observations were of far less importance than we would expect; simple schematic models for the movements of the celestial bodies were for a long time considered sufficient. The earth was the ground on which people stood; its shape was not a topic of astronomy. The gods lived in heaven, and the visible sky was the lower boundary of the gods' world. We do not even know for certain whether the Babylonians considered the sky a sphere. We also have to forget the modern differentiation between astronomy and astrology; it would have made no sense to a Babylonian.

The goal of the Babylonian scholars can best be called knowledge of the sky without any qualification whether it is a science or not -this question would require a different lecture.

When writing on clay tablets was invented towards the end of the 4th millennium BCE in southern Mesopotamia, it was used to make possible the administration of agriculture and animals in large households; the records concern income and expenditure of goods, the responsibility of officials, etc. On the other hand, among the early cuneiform texts there are lists of professions, animals, place names and all kinds of objects. These lists were probably used for learning, but they also present the words in a meaningful sequence. Still during the 3rd millennium, these lists are greatly expanded to include many objects of everyday life. Among them, stars and constellations are mentioned too. No principle is evident in the order of these celestial objects.

It is only in the 2nd millennium BCE that texts appear which are dealing with phenomena in the sky. In these texts we see a desire to find out how the skies are organized, and a belief that this organization can be understood and described in relatively simple ways. The use of observation is limited: while obviously one must look at the sky to be able to say something about it, schematic approaches were predominant (Figs. 1 and 2).

An example for this are the so-called Three-stars-each texts which probably go back to between 1500 and 1000 BCE. They list, for each month of the Babylonian calendar, three constellations which are supposed to become visible in this month: one constellation to 
A88YRIAN PLANISPHERES.

K. $14943+81-7-27,94$.

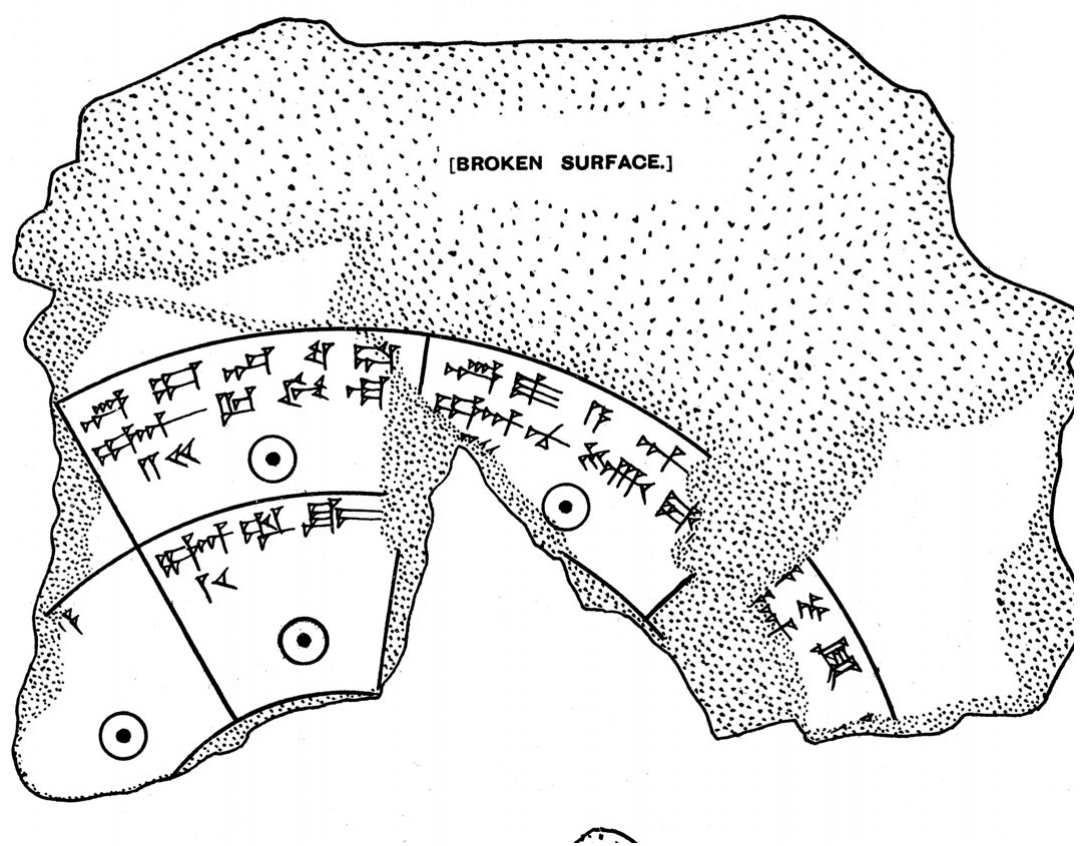

Figure 1.

the North, one near the equator, and one to the South $\dagger$; it is furthermore stated that the same constellations disappear again after six months. This gives a neat scheme of 36 constellations from whose risings one could tell the time of the year. However, it would not work in practice: first of all, the period of visibility is different for stars depending on their declination; it is simply incorrect to assign to all of them a visibility of six months. Then, the Babylonian calendar is not easily attuned to the solar year so that heliacal risings of stars will not stay in the same month in every year. And, just to indicate that we are far from a secure interpretation, the lists also include planets, which are subject to entirely different visibility conditions, independent of the time of the year; finally, there are even variant forms of the list which have only ten constellations -instead of 12 - which makes an alignment with the months of the year impossible.

The Three-stars-each lists may be seen as attempts to organise what is known about stars. At about the same time an astronomical text was compiled, called Mul-Apin (which means Plough star) after its first word. It is only attested on tablets from the 7th century onwards, but probably goes back to the 13th century BCE.

It contains:

(a) Six lists of stars and constellations. The first list is arranged approximately by the place in the sky where the stars are, beginning in the northern part. The second list contains the dates when certain constellations rise heliacally, in an idealized calendar. The third list gives constellations which rise and set simultaneously. A fourth list is based on the second, giving the time differences between the heliacal risings. The fifth list combines stars that culminate with those that rise at the same time. Finally, there

$\dagger$ to avoid misunderstandings: there is no word for equator in these texts. 


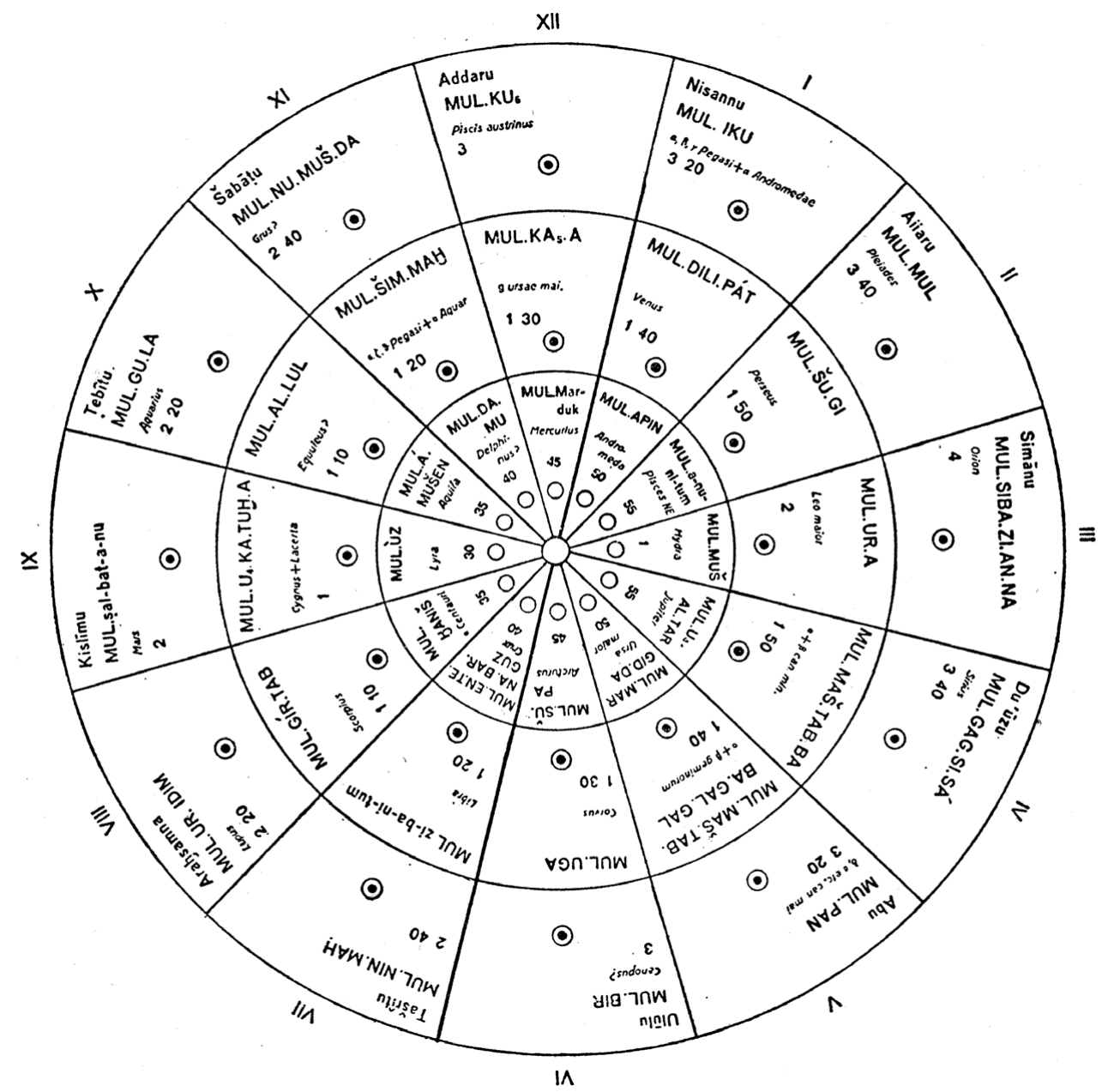

Figure 2 .

is a list of 18 constellations which stand in what is called the path of the moon, i. e. the ecliptic.

(b) For the planets, the periods of the visibility and invisibility are presented; these do of course vary, and the times given are only approximative.

(c) There are two schemes for intercalation, one using the time of the solstices and equinoxes, the other heliacal risings of certain stars.

(d) Mul-Apin also contains a table for the length of the shadow of a stick at different times of day, and in different seasons; and a table for the amount of water in a water clock depending on the season.

At the end of the text, a number of celestial omens are appended.

In the 7th century BCE we can see for the first time that Babylonian scholars try to foresee when and where certain phenomena in the sky will happen; I return to possible reasons for this later. From this time on, regular observations were made and collected. The clay tablets with collected observations are nowadays called astronomical diaries; they contain the following information:

For the Moon, the dates of conjunctions with stars near the ecliptic are noted, together with the distances between the moon and these stars. The time intervals between moon- 


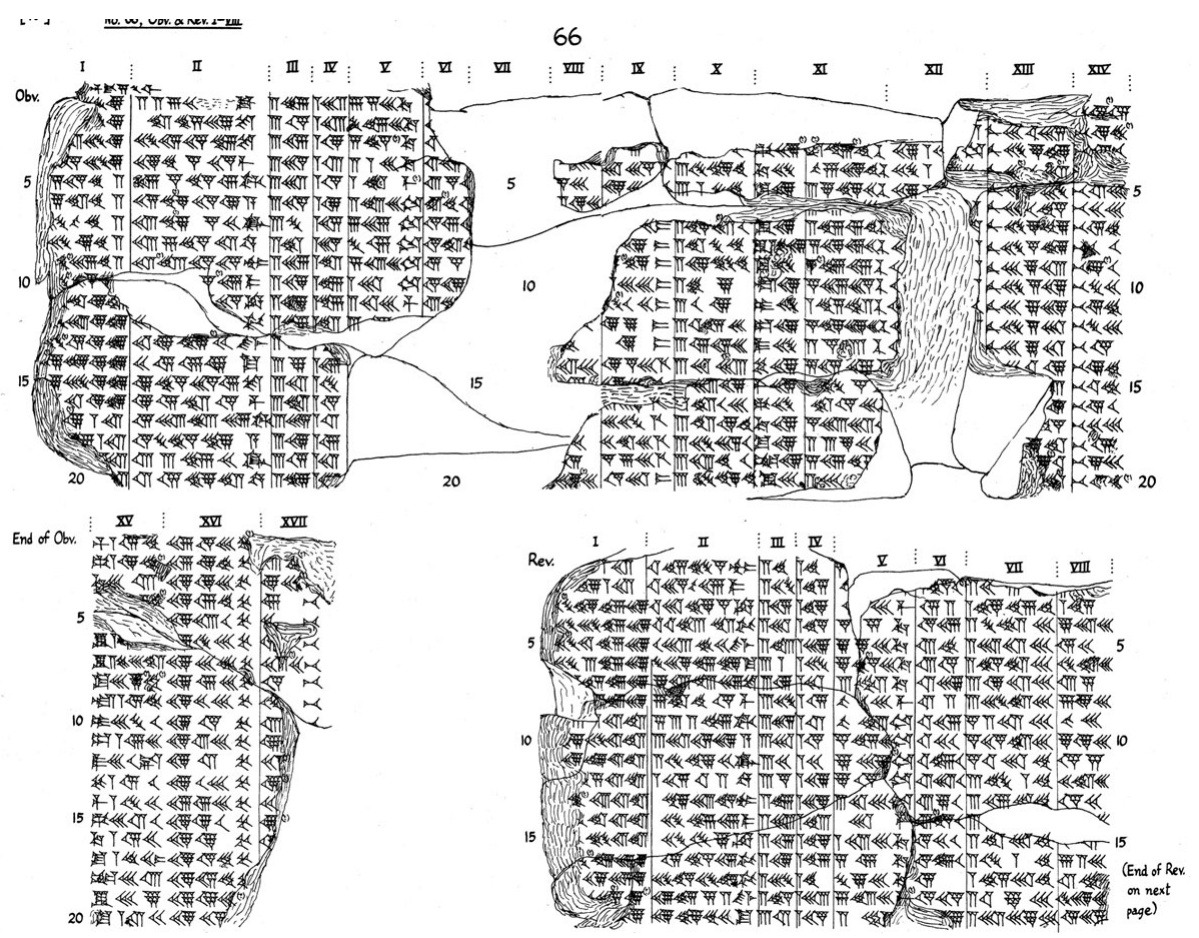

Figure 3.

rise or moonset and sunrise or sunset are measured before and after the conjunction of sun and moon, and also before and after opposition (full Moon). Eclipses of Sun and Moon are described in detail.

The dates of first and last visibilities of the planets, partly also the stationary points, are noted, and the planets' conjunctions with stars.

Apart from astronomical information, the diaries also report the prices of main commodities like barley or dates, the level of the river Euphrates, and memorable events.

The material in these diaries is the basis for mathematical astronomical texts. In the time from about 500 BCE onwards, the Babylonian astronomers succeeded in calculating the phenomena of the moon and the planets with surprising reliability, using mathematical methods based on relatively simple arithmetic, but cleverly organised. It would take far too long to explain these calculations; let me just show you a tablet which in no less than 17 steps finds the dates of successive new moons for the years 104-101 BCE. The calculations take into account the various components of the lunar motion, without any geometrical model of the size and distance. It is a remarkable intellectual feat to consider a complicated movement as made up of several components, and to calculate them one by one (Fig. 3).

Let me now turn to the relations of astronomy with Babylonian society. The astral component of religion should be mentioned first. Stars can be manifestations of the gods, but they are not the only such manifestations. Gods were also present in their cult statues which stood in the temples. Prayers can be addressed to gods in their astral appearance, and incantations make use of the power of stars. But there is no influence of changes in astronomical knowledge on such religious practices.

While the movements of the stars may be of interest only to some people, the calendar and the measurement of time is important to society as a whole. The Babylonian calendar 
uses lunar months which begin with the first visibility of the lunar crescent after its period of invisibility. These months are either 29 or 30 days long; 12 such months have approximately 354 days. Since such a year is by 11 days shorter than a solar year, a month is added when the seasons do not fit the calendar any more; one wanted the seasonal activities to remain in the same months. In early times, intercalation was decided by the king, and was rather irregular. The intercalation rules contained in Mul-Apin, mentioned above, would have resulted in more regular intercalation, and it seems that to some extent these or similar rules were applied since the 7th century BCE. At the latest around 500 BCE, a cycle of 19 years with 7 fixed intercalations was introduced. From then on, intercalation was predictable.

On the topic of time measurement, Mul-Apin gives a list of how much water has to flow in or out of a water-clock to measure the length of daylight which varies through the year. We can assume that water clocks were in fact used even if none have been found. We do not know what type of water clock was used in Babylonia.

Another way to measure time at night was to observe the culmination of stars. A list of appropriate stars was included in Mul-Apin. From a letter of the 8th century BCE we learn that culminating stars were used not only for astronomical purposes: in the letter, a storm at night is reported to have lasted from the culmination of the Circle constellation to the Triplets constellation. This corresponds to 1.5 of our hours.

The complicated calculations which I mentioned before are very impressive, but they constitute only a small part of the Babylonian tablets related to astral lore. Most of the tablets concerning the sky are celestial omens. I deliberately use the term celestial, and not astrological. Strictly speaking astrology, as it developed in Hellenistic times, implies the belief in powers emanating from the stars and planets which then cause certain things on earth to happen. It is not possible to escape from the fate predicted in this way. Such a belief is not found in Mesopotamia; there the events in the sky are seen as messages from the gods, meant to warn humans of potential future events. If nothing is done, these events will happen. But it is possible to prevent the predictions from becoming true, by means of prayers, rites and sacrifices. The predicted events are not inevitable. So the neutral term "celestial omens has been favored by scholars in recent years to avoid the association with the astrology of Hellenistic civilisations.

Celestial omens are among the oldest ones attested so far. The first collections of them appear in the first half of the 2nd millennium BCE, and concern mostly lunar eclipses. These texts already have a highly structured form, which suggests that they were developed by scholars skilled in the observation of patterns of astronomical phenomena. It should be emphasized, however, that omens from the sky did not play an important role in early times. Divination from the liver of sheep was far more frequent. Only in the first millennium BC did celestial divination become a dominant source of signs. The interest in it, however, had existed for centuries before that, and the pertinent omens were collected like others too. This finally led to the organisation of celestial omens into an extensive edition comprising about 70 tablets.

Here you see one exemplar of celestial omens (Fig. 4). According to its beginning words the ancient scribes called the collection of celestial omens Enuma Anu Enlil which means When the gods Anu (and) Enlil, and is the beginning of the introductory sentence When the gods Anu, Enlil and Ea designed heaven and earth. The celestial omens in Enuma Anu Enlil are arranged in four sections: Signs from the Moon, with a separate chapter on eclipses; signs from the Sun, again including eclipses; signs from weather, including earthquakes; signs from the stars and planets. Several exemplars of this celestial omen collection were kept in the famous library of the Assyrian king Ashurbanipal from the 7th century. It is certain, however, that the edition of Enuma Anu Enlil was achieved already 
1526

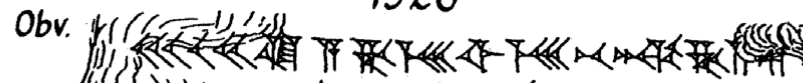

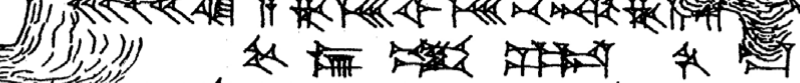

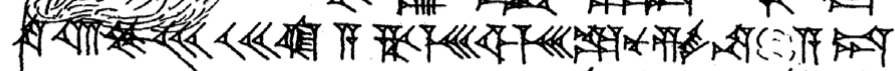

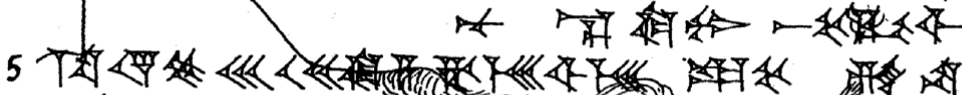

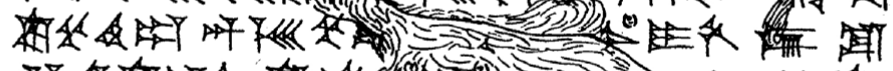

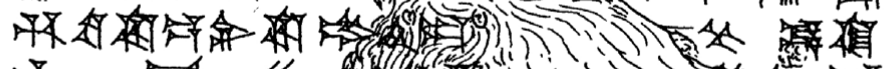
म 4 世

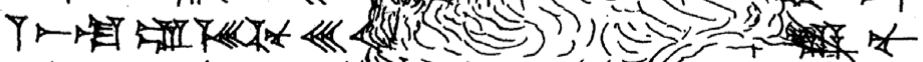

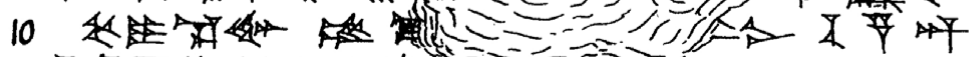

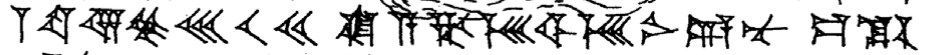

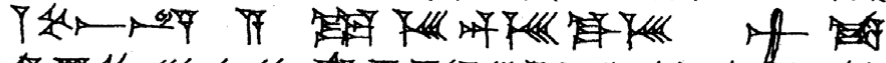

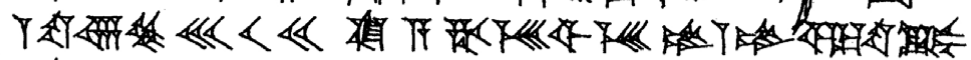

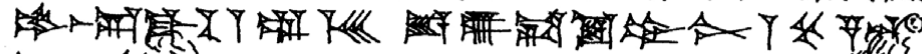

15

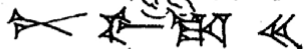

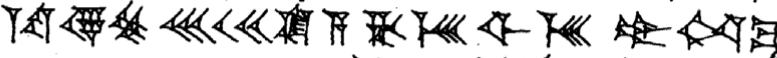

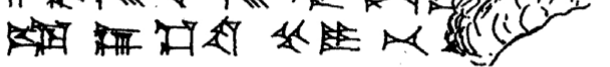

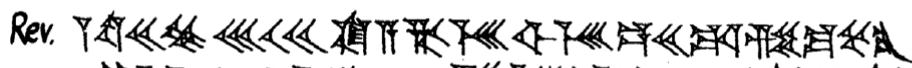

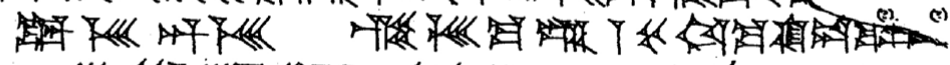

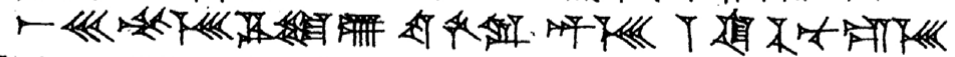

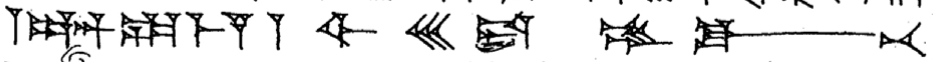

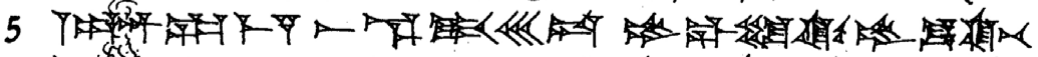

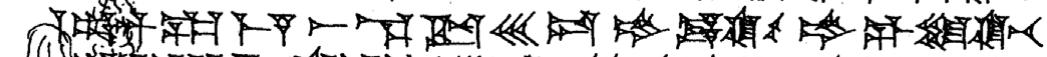

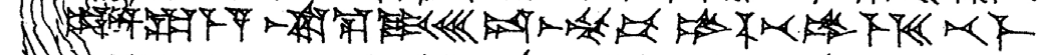

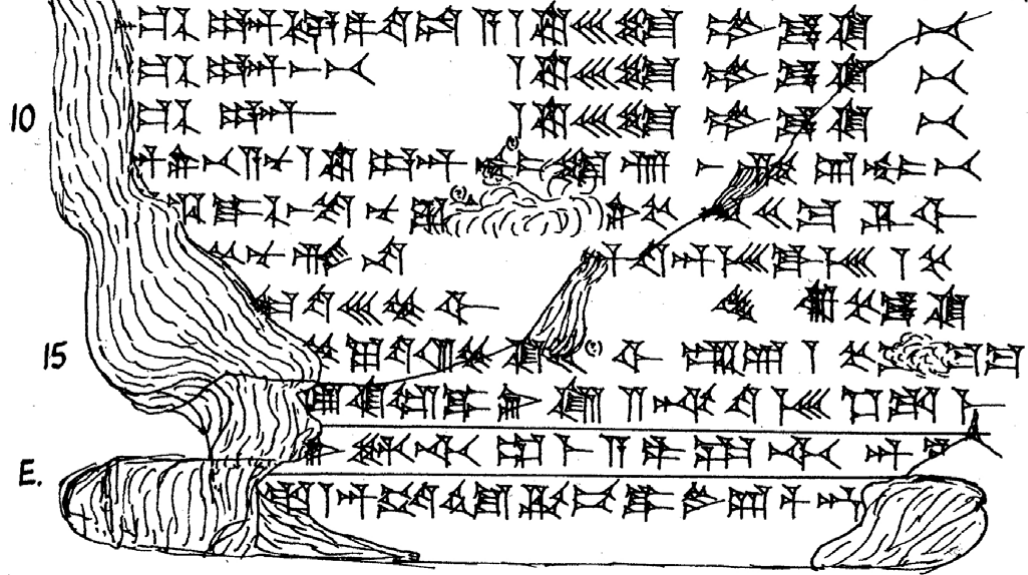

Figure 4. An example of celestial omen.

earlier, although we cannot say exactly when. It seems to have been considered as a final standard and an authoritative work by the scribes of Ashurbanipal, but we nevertheless find copies from the Neo-Babylonian period after $600 \mathrm{BCE}$, later than Ashurbanipal, which have added variants or explanations and interpretations. So the work on the great 


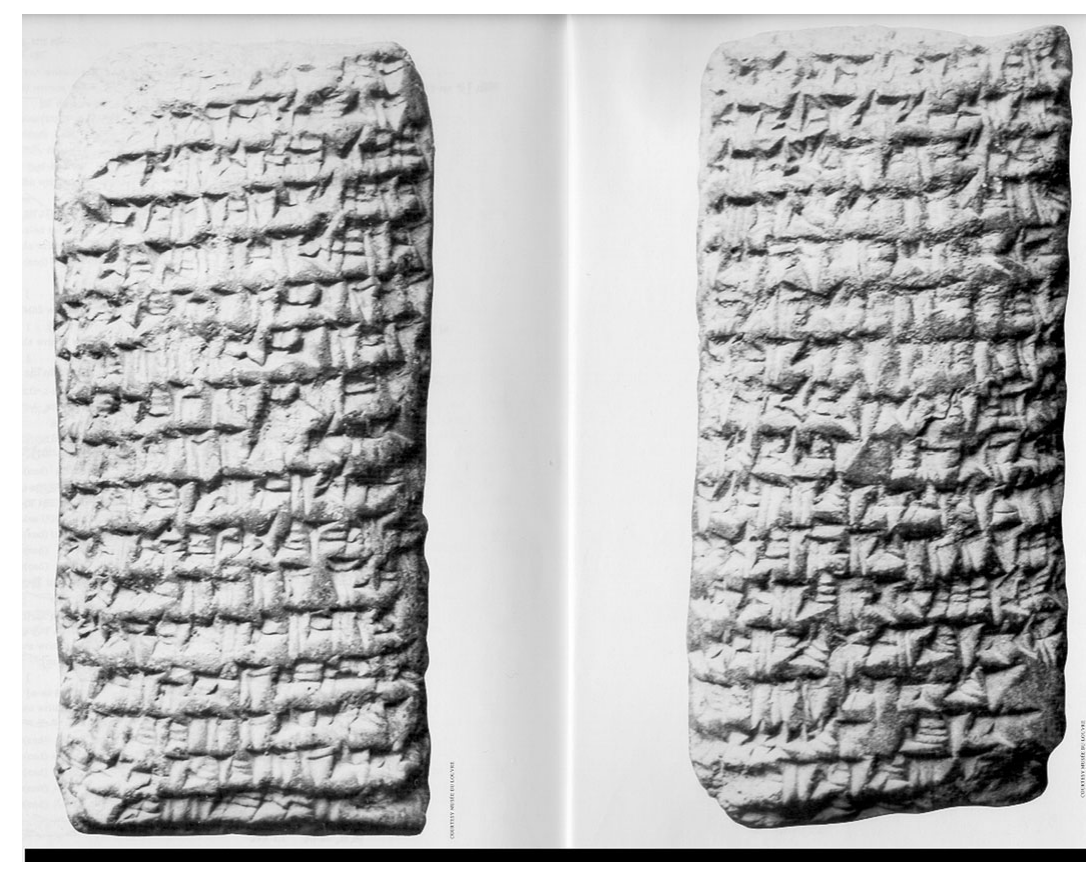

Figure 5.

collection of celestial omens continued down to the latest period of cuneiform civilisation (Fig. 5).

Especially informative is an archive of the Assyrian kings Esarhaddon (681-669 BCE) and his son, the just mentioned Ashurbanipal (669-631 BCE), from the 7th century which was found (mostly broken, of course) in the ruins of Nineveh in present-day Mosul. It consists mainly of letters sent to the king from various officials and experts in different cities of the empire. At that time, Babylonia was a part of the Assyrian empire; both countries had more or less the same language, and their culture had formed through centuries of interaction. Some of the letters in the royal archive deal with military or political affairs: for instance we have the information which agents of the Assyrians sent back from the border areas with friendly or inimical states. Several hundreds of these letters are Reports from experts in celestial omens. I like to call these people experts because they were among a very small group who were able to find and interpret omens. Not everyone could do this; it needed a long education, if only for learning to read and write clay tablets which was necessary to consult the collections of omens. The king depended on the experts for getting the correct explanations of omens, so that he could act accordingly. Recently, someone has put forth the plausible conjecture that king Ashurbanipal, who in his inscriptions boasts that he could read and write, learned this art because he wanted to be able to check on his scribes and did not like to be dependent on them. Most kings of course could not read or write. In some sense, one can also call these expert scribes "scholars" because they are trained in a tradition and know how to apply this to new observations. They also try to find new interpretations and explanations within their tradition, as scholars do in our understanding.

What do the experts write to the king? There are two types of messages: letters and reports. The letters have a certain formulary: first the king is addressed, then follows the name of the sender, and a number of polite sentences. I give you an example: "To the king my lord, your servant Adad-?umu-usur. May the gods Nabu and Marduk bless the 


\section{Obverse}

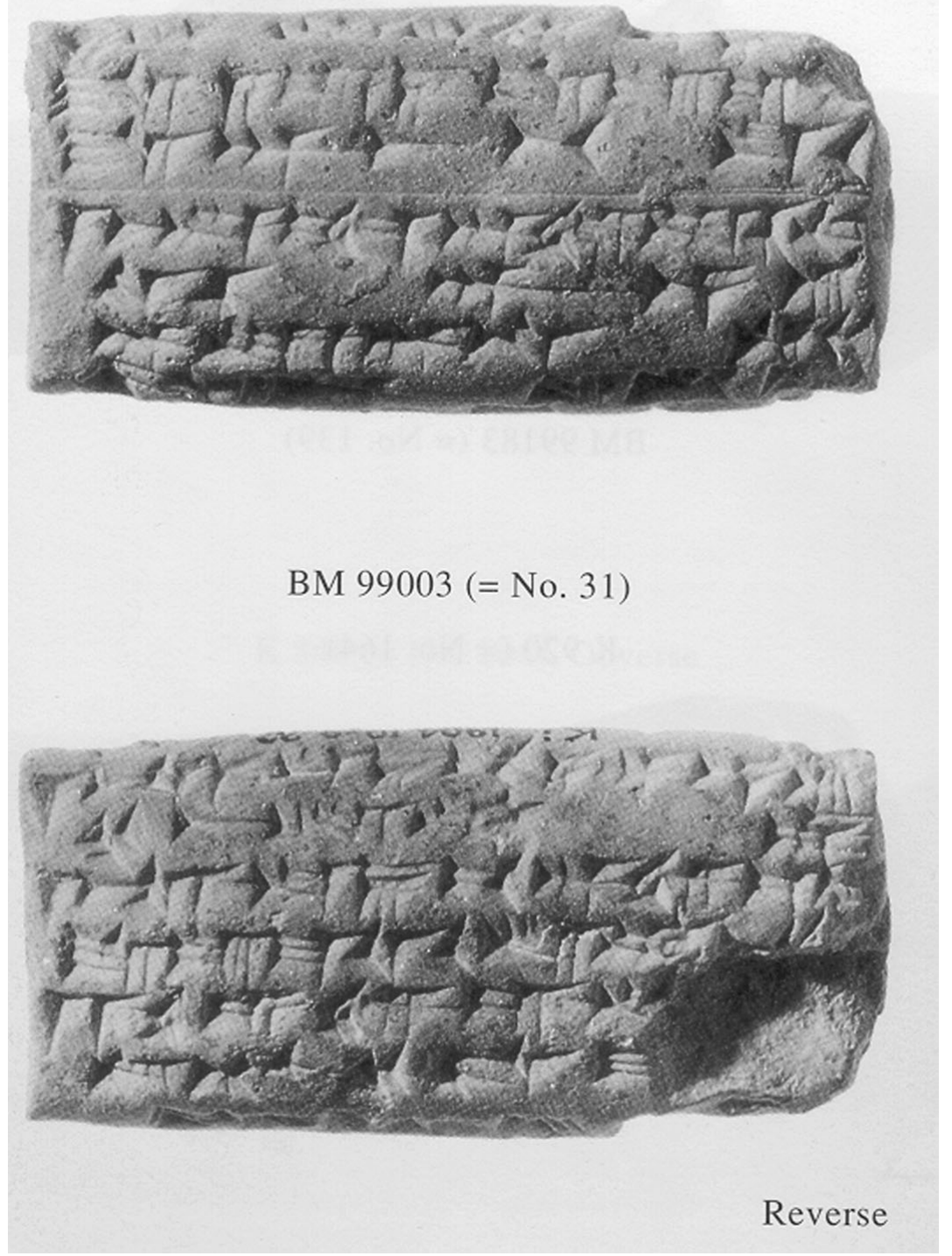

Figure 6.

king my lord! May they grant the lord of all kings, my lord, happiness, health, a long rule and a long life!". After this greeting, the main part of the letter follows. The king is always addressed in the third person, as "the king, my lord"; very rarely do scribes use the second person and say "you" to the king (Fig. 6).

In the reports, no introductory address to the king appears; the text begins immediately with omens. At the end, the name of the scribe is usually given. Letters and Reports differ also in their shape: letters a re longer than wide, Reports wider than long.

Here are some examples of omens from reports: "If on the 14th day of the month the Moon and Sun are seen together: the country will become happy; the gods will think favorably of Babylonia; people will speak the truth to each other." Or: "If Jupiter stands inside the Moon: in this year the king will die". Strictly speaking, it would have been 
enough just to quote the omens; the first part of the sentence, the protasis, always implies some observation, and the second part, the apodosis, gives a future event. Nevertheless, the scribes frequently add explanations. Such explanations are necessary when it is not immediately evident how the observation described in the protasis would have appeared in the sky. But the explanations are also used in a different way. For each planet, there were several constellations of fixed stars which were considered equivalent to the planet. The principle behind these substitutions of planets for constellations is probably the color of the planets and of certain fixed stars. A red star can be replaced by the red planet, which is Mars. The omen can therefore be given by Mars. In this way, the scholars found new meanings in the traditional omens, replacing fixed stars by planets. Let me again illustrate this by an example: "If in the sixth month the Kidney star becomes visible: the harvest of the country will be good". The Kidney star is Mercury. So the expert has found a omen which he could quote for the appearance of Mercury, and which had the additional advantage that the prediction is a favorable one. Or a similar case: "Saturn became visible in the constellation Leo". This observation is followed by this omen: "If Leo is dark: for three years lions and wolves will kill people and interrupt traffic with the Westland". To understand this, one has to know that Saturn was considered a dark planet; by appearing in the constellation Leo, it made this constellation dark. In this way an omen concerning fixed stars could be used to interpret a planet's appearance.

In their letters, the scribes give more explanations than in the Reports, and, in case of bad omens, they frequently make proposals how the danger could be averted. One way to do this is the so-called namburbi ritual. Namburbi is a Sumerian word and literally means its loosening, its disspelling; what is meant is that the evil which is imminent can be untied like a knot so that it does not hold together any more and does not happen. There are namburbi rituals for all kinds of bad omens, depending on the object that was the source of the omen. They are used especially for those everyday happenings which predict something unfavorable, like the sudden appearance of insects in a house or the sounds of certain birds. Since it is difficult to imagine all kinds of bad omens in advance there is also a general all-purpose namburbi ritual which is applicable to everything. The namburbi rituals are also well-known to the king's experts who frequently advise him to have some such namburbi performed.

The most remarkable case of the endeavours to protect the king of the consequences of dangerous omens is the so-called substitute king. Certain omens from lunar eclipses indicate the death of the king, not always of the Assyrian king, but sometimes. In order to protect the king, some other man was put on the throne under elaborate ceremonies. This substitute was given royal dress and insignia; he had servants at his disposal and could appear like a king. Of course he had no influence on government or on the army. The purpose of his enthronement was to make the bad omen fall on him; for this reason the omen was recited solemnly to him. The real king kept out of sight as far as possible, did not leave the palace and performed no public function. It was even forbidden to address him as king; in the letters which are written at such occasions, the scribes call him my lord farmer. Since the period of validity of such an omen was 100 days, the king would have to wait 100 days and hope that the substitute king would drop dead soon. However, during this time of the greatest power of the Assyrian empire, the experts advising the king did not leave the outcome of the procedure to chance. There are letters which contain sentences like the following: "as regards the substitute king: if the farmer my lord agrees, he can go to his fate tomorrow; but if not, he may sit on his throne for the full 100 days". In plain words, it was clear that the substitute king would be killed $\dagger$,

$\dagger$ to go to his fate is a euphemism for to die. 
and the adviser asked the real king when he wanted this to be done. In any case, it was done shortly before the 100 days were over so that the omen had actually come true. There are three different cases of such substitute kings attested during the time covered by the archives of Nineveh. Several questions can be asked about it: how anyone would be willing to be substitute king (but of course in the Assyrian empire most people could not say no if there was a command of the king); what the king and his advisers thought about the gods who in a certain sense were to be tricked by this procedure. It is certain that the whole procedure was considered necessary; even while everything was done to keep the Assyrian king out of danger, it cannot have been fun to hide and not appear in public, not to speak of the numerous rituals that were performed on the real king in addition to having a substitute. And in spite of all this, the king may have had great fear in his heart whether the omen would not after all hit him instead of the substitute. We have a story of a king in the beginning of the 2nd millennium BCE who also had a substitute put on his throne; but, as the text says, the king died in his palace from eating a hot soup; and the substitute did not get up from the throne but stayed there and became king. Now whatever the exact circumstances of this story (which cannot be proven true from contemporary documents), it may have been known also to the later kings of Assyria, and could cause them many sleepless nights. In any case, the substitute king is perhaps the most impressive example to be found for the belief in the importance of omens.

The main problem with celestial omens (as with others which are unprovoked and simply happen) is that they cannot be repeated in case of doubts. This problem was solved by resorting to extispicy, the inspection of the entrails of sacrificial animals. There were always sheep available, at least to a king, that could be sacrificed and inspected. The oldest known case is from the city of Mari in nowaday Syria, from the first half of the second millennium BCE. A lunar eclipse was observed, but its significance was unknown. So it was interpreted by means of an extispicy. In a similar way, king Sargon II of Assyria, when on a campaign in the east of Assyria in 714 BC he was confronted with a celestial omen from a lunar eclipse, had his diviners inquire about its meaning by extispicy. In this case, one can have doubts whether the outcome was not determined by the king in advance. He could have the extispicy repeated if he did not like its result.

The increased use of celestial omens during the 8th and 7 th centuries, especially at the Assyrian court, has led to the general assumption among modern scholars that it was interest in omens which brought about the enormous development of Babylonian astronomy in the following period. There are in fact some points that can be made in favor of this explanation; but it should be kept in mind that most of the texts which we call astronomical show no sign of being used in connection with omens. The computations of the Babylonian astronomers are directed towards certain phenomena of the moon and the planets, like first visibilities or stationary points. They do only rarely try to find the position of a planet at a given time, regardless of the phenomenon. The omens, on the other hand, contain in their protases frequently such phenomena, for example: "If Jupiter becomes visible in the constellation of Cancer: the king will have a long reign". It may therefore have been of interest to compute in advance when Jupiter would become visible in Cancer. Similar things could be said about the eclipses which necessitated the enthronement of a substitute king: if one knew in advance that such an eclipse would occur, the preparations could be made earlier. The scribes at the Assyrian court who interpreted the eclipse omens did indeed try to foresee when an eclipse would happen. They could already tell when an eclipse was not possible; but positively predict a lunar eclipse they could only a few days before it happened. Now to us (or at least to me) there is a logical problem here: if a sign can be computed and predicted, it cannot at the 
same time be given freely as a warning by the gods because they have no choice; the sign will happen anyway. Probably a Babylonian would have answered that the gods could certainly prevent a sign from happening. Be that as it may, this consideration was not a problem to the Babylonians: even in times when the astronomical texts were successful in predicting planetary phenomena and lunar eclipses, omens were still copied, as we know from omen tablets dated to the Hellenistic period. We do not know who used them, by the way; the Seleucid kings probably had their own divination experts, not necessarily Babylonian. In this period both astronomy and omen lore were maintained by scribes employed by the temples in Babylon and Uruk, maybe also in other cities. It should be noted that the same scribes who copied tablets with omens also wrote astronomical texts. They have the professional title of scribe of Enuma Anu Enlil which is the name of the collection of celestial omens, but they are engaged in producing the astronomical tables which look to us like precursors of modern natural science. Of course this is a false impression. Since the same people work in both fields there is no reason to assume a conflict about methods. Even if the astronomical tables and the omens belong to different genres, both are part of the same tradition which was acquired and transmitted by the scribes, now working no longer for the king but for the temple. So we can say that the temple organisation was interested in keeping a tradition, even if we do not know whether it was still used for practical purposes.

In the second half of the first millennium $\mathrm{BCE}$, new techniques were developed to gain insight into the future. One of them is found in what is somewhat loosely called horoscopes. It is not really correct to call these Babylonian texts horoscopes because they lack the consideration of the point of the ecliptic rising at the time of birth, which is called horoskopos in Greek. So the very detail from which the name horoscope is derived is not present in them. There are about 30 such texts known; the earliest two of them are datable to 410 BCE. They may be considered precursors of later Hellenistic horoscopes in the sense that they record computed astronomical phenomena on the date of birth. Let me quote one of these Babylonian texts to give you an idea: "Year 169, month XII, night of the 6th, beginning of the night, the Moon was 1 cubit to the west of Beta Tauri. In the morning, the child was born. At that time, the moon was in the beginning of Gemini, the sun in Pisces, Jupiter in Libra, Venus and Mars in Capricorn, Saturn in Leo". Note that no predictions about the future life of the child are added in this text. There are other horoscopes which do contain predictions, but they are rare.

Babylonian horoscopes are computed for private persons, not only for the king. This could be called a democratisation of celestial predictions. Certainly these texts are a use of astronomy by the society at large. Two elements are characteristic of these late Babylonian astrological texts: first, the Zodiac, consisting of 12 equal signs of 30 degrees each. The Zodiac was only invented in the 5th century BCE; earlier, the Babylonians had ca. 17 constellations, of different size, along the ecliptic. The second element are socalled nativities, i.e. personal predictions from celestial phenomena at the time of birth. Predictions for private individuals are markedly different from the Babylonian tradition of omens from the sky, which concern the king or society as a whole, but not single persons. Furthermore, the emergence of these horoscopes was dependent not only on the invention of the zodiac and on the interest in personal prediction, but also on the astronomical texts that were available at the time. The main content of a Babylonian horoscope was a record of positions of the planets, Sun, and Moon on th e date of birth. These positions are mostly given just for a zodiacal sign, only a few horoscopes give specific degrees within a zodiacal sign. It would not have been easy to obtain precise positions from the astronomical computation texts (of which I showed you a picture earlier), because these computations do not produce positions at any desired date, but only for the characteristic 
phenomena of the planet, like first and last visibilities etc. Some kind of interpolation could of course be used, but such a procedure is almost unattested. On the other hand, there is a group of astronomical texts which we call Almanacs. Here is a quote from one them:

"Month I, the 1st (of which followed the 30th of the preceding month). Jupiter in Taurus, Saturn in Scorpius, Mars in Pisces. The 15th, first sunrise before moonset. The 19th, Jupiter's last appearance in Taurus. The 26th, Mars reaches Aries. The 27th, Saturn's acronychal rising. The 27th, last visibility of the Moon. The 29th, first appearance of Pleiades in the East.

Month II, (the 1st of which is identical with) the 30th (of the preceding month). Saturn in Scorpius, Mars in Aries. The 2nd, Sirius' last appearance. The 6th, Venus' first appearance in the West in Gemini. The 6th, Mercury's first appearance in the East, omitted. The 15th, first sunrise before moonset. The 20th, Jupiter's first appearance in the end of Taurus. The 20th, Mercury's last appearance in the east, omitted. The 26th, Venus reaches Cancer. The 28th, last visibility of the Moon. The 29th, Jupiter reaches Gemini".

These Almanacs contain predicted data of the kind needed for composing a horoscope, like in which zodiacal sign the different planets were during a given month etc. It is possible that the composition of horoscopes was one of the reasons for producing the Almanacs. Most likely, the data in the almanacs were ultimately taken from the astronomical Diaries which I mentioned earlier. This was done in the following way: Astronomical phenomena re-occur after certain periods; in particular, they re-occur on the same or almost the same date in the Babylonian calendar after a certain number of years. These periods, which are different for each planet, were known to the Babylonian astronomers, and so they copied the data from the year that was one period earlier in order to predict the next occurrence of a phenomenon. The Diaries contain the necessary information, but one has to search for it, and this is quite a lot of work. In this way the data for a Babylonian proto-horoscope could be prepared.

Omens from the situation at birth existed in Babylonia independently of the horoscopes. This tradition of omens derived from birth is old and a well established part of the general omen lore of Mesopotamia. The majority of the horoscopes do not give any predictions about the future life of an individual, but if they do, these predictions are quite similar to the nativity omens which we know from the older sources just mentioned. So the horoscopes which do not give predictions, may have been only th e preliminary material that would provide the possibility of a prediction by means of omens which one had to look up in a different tablet. The situation in the sky on the date of birth seems to have been interpreted as a group of signs or celestial omens. In this understanding, horoscopes would not be a completely new form of astrology, but an expansion of the celestial divination long practiced in Babylonia.

This use of astronomy by Babylonian society is still followed by some people today. 